\title{
Back to basics. The value of clinical examination and traditional human contact between a patient and his physician compared with procedural standardized virtual or presential consultation: a narration
}

\author{
Dominique F. Gazielly ${ }^{1} \cdot$ Marius M. Scarlat $^{2}$
}

Published online: 25 May 2021

(c) SICOT aisbl 2021

Modern medicine and surgery are a small part of a long history of care and assistance that sine millennia the mankind aimed to provide in helping people, fighting with sickness, sufferance, pain, and handicap.

Modern orthopaedics became a surgical discipline with more and more procedures offered today on the basis of better anatomic and physiology understanding, and the progress toward specialization is recent and in one century the changes were so important that what we are used to define in our days as normality was eventually science fiction by the time our grandparents were young.

The changes in medicine are spectacular lately. This resulted in an unprecedented rise of the quality of care, patient's safety, and satisfaction [1]. Computer science and networking made possible virtual clinics and remote-controlled evaluations and interaction, even some procedures [2].

In our days, when a viral pandemic made circulation, quite difficult if not impossible, the orthopaedic specialist is constraint in his working habits and kept in his hometown with limited scheduled cases. Human contact was mediated with social distancing and virtual clinics were offered; however, many were unable to adapt fast to such a brutal change and images from memory strike back.

June 20, 1995, a city in central France, ...Françoise accompanies her mother, aged 76, widowed for ten years, to her consultation appointment with one of the few French orthopaedic surgeons specializing in shoulder surgery, who has just organized a major congress on

Marius M. Scarlat

mscarlat@gmail.com

1 Clinique du Genolier, 1272 Genolier, Switzerland

2 Clinique Chirurgicale St Michel, Groupe ELSAN, Toulon, France this subject in his city. Françoise's mother, Raymonde, is right-handed. Her whole family suffers from osteoarthritis. She has worked a lot since her teenage years in weaving and has used her right shoulder in these looms which are her whole professional life. She can't sleep on her favourite right side. This pain bothers her in all movements of daily life, e.g., ironing, cleaning, shopping, taking a pan or a plate from a shelf, and eating. She has been followed for three years by a rheumatologist who talks to her about osteoarthritis, gives her anti-inflammatory drugs which affect her stomach, has already given her three infiltrations in office without improvement, and tells her that there is no solution to her problem. The surgeon who receives her in his office, calm, in his fifties, inspires her confidence from the start. He asks Raymonde a lot of questions about her history, her pain, how long it has been onset, how uncomfortable she is with everyday activities, if she is taking any medication, and what treatment she has had since the start, and her daughter Françoise insists on the fact that this pain is becoming unbearable and prevents her mother from sleeping, which tires her more and more. The surgeon notes all these elements in a file brought to him by his secretary. Then, he takes Raymonde to her exam room and asks her to take off her blouse. Françoise helps her mother who is having great difficulty removing her right sleeve, and the doctor watches this scene with attention. Then, he examines Raymonde, starting with the left shoulder, whose mobility is almost normal and slightly painful. When he switches to the right shoulder, he immediately notices that the anterior elevation is limited to $100^{\circ}$, the internal rotation does not exceed the level of the sacrum, and the external rotation of the elbow to the body barely reaches $20^{\circ}$. Mobilization of the right shoulder is very painful and causes a hard rubbing noise, perfectly audible. Hawkins, 
Yokum, and Jobe's maneuvers are negative for the left shoulder, and impossible to perform on the right shoulder due to the severe stiffness. The doctor clinically suspects right osteoarthritis, confirmed by the X-rays that he asked the patient to take before the consultation, a face in neutral rotation, a Neer profile, and an axillary profile. The standard radiographic assessment shows a centered osteoarthritis, with a large osteophyte at the lower pole of the humeral head. There is no ascension of the humeral head. The axillary profile shows that the glenoid is centered and this is what was defined later the type A1 arthritic glenoid in the Walch classification. Neer's profile shows no acromial hook, as in the opposite shoulder, for which a standard radiographic assessment was systematically requested. Overall, the exams show early osteoarthritis, which may have an impact on the post-operative rehabilitation, if the placement of total anatomic shoulder prosthesis is considered. In office, the surgeon takes all his time to explain to the patient that she is diagnosed with shoulder arthritis, probably of familial origin, that this has been evolving for a long time, and that it moreover begins at the level of the left shoulder where Raymonde admits having some pain in certain movements. He explains that he can make her right shoulder painless and mobile by placing an anatomical sliding prosthesis. He explains to her on the radiographic assessment what the placement of a total prosthesis consists of. He shows her an anatomical prosthesis with a stainless steel prosthetic head, the chosen size of which will best adapt to her anatomy with a polyethylene glenoid placed with cement and compacted cancellous bone in front. He specifies that the humeral rod will also be cemented because his bone is a little osteoporotic. He suggests to see her again with a magnetic resonance image (MRI) exam which will specify the condition of the rotator cuff which is the real engine of the future prosthesis. Above all, he asks her to think, gives her the address of another shoulder surgeon to get a second opinion, and tells her there is no rush. Finally, he explains that post-operative rehabilitation is very important, and advises her to exercise flexibility with a physiotherapist who specializes on the shoulder and who will take care of her if she has an operation. So she will know him beforehand, and be well prepared. He takes the time to telephone the physiotherapist in front of the patient, to explain the proposed treatment. Three months later, Raymonde will have surgery under general anaesthesia performed by the surgeon she has chosen, with the insertion of an anatomical total shoulder prosthesis. The outcome is good, as expected because this procedure usually improves the patient's shoulder and quality of life [3, 4]. The rehabilitation will last 6 months, with the physiotherapist who took care of her before the operation. She will be very satisfied with the functional result obtained and since the pain has completely disappeared, she can sleep well and do whatever she wants in everyday life. She is happy to accompany her grandchildren to the pool and swim with them.

In our modern times, Françoise, now 76 years old, suffers from a right shoulder, like her mother at the same age. The latter, who passed away a few years ago, has never suffered from her operated shoulder again. Her retired surgeon is no longer operating. She made an appointment online with a young surgeon, whom her general practitioner knows and who operates in a renowned hospital establishment. She has suffered from her right shoulder since a fall that occurred at home six months ago, preventing her from sleeping and completely raising her arm, taking a bottle full of water at arm's length, but above all from playing tennis in double with her girlfriends.

When she arrives at $10 \mathrm{AM}$ in the waiting room of the orthopaedic surgery department, more than 30 people are waiting in a huge hall which gives access to the offices of the different specialized units, e.g., hip, knees, spine, shoulder, and hand. Barely seated, a uniformed employee of the private hospital approaches her with an iPad and asks her many questions, such as age, medical and surgical history, name of the attending physician, reason for the consultation, name of the specialist who she comes to see all the information she sends to the secretariat of the shoulder unit. She is given a number which should be displayed on an electronic counter when it is her turn to consult. Then, 20 minutes later, she hears: "number 48, please come to gate six." Arrived at the secretariat of the shoulder unit, a secretary asks her to move into box number four, impersonal, without window, where she waits about ten minutes before a young man, in scrubs, very professional; maybe too professional. "Do you have anything to add to what you said earlier to the hostess ...?" He asks her. "You most likely have a ruptured rotator cuff, and I have to have you undergo an Arthro-MRI this morning". "Doctor L... will see you after the examination... please go to the Radiology Centre, in the first basement, ground zero, elevator five." After 30 minutes of waiting, and after having undergone an injection in the arm and having remained more than half an hour in a tube, where an impersonal way asks him not to move, between sequences of bizarre noise, like machine gun bursts... A young and pretty technician gives her a small bottle of water and asks her to go up, by elevator five, to door six, where the Doctor will explain everything... After 30 minutes of waiting, the secretary makes her enter the office, spacious, bright, ultramodern, and stripped down, of Doctor L..., a highly specialized surgeon in the shoulder, with whom she has an appointment. The assistant she saw before the imaging is standing next to the seated surgeon, and they watch together images scroll on the computer. She hears comments "... there is nothing left, not fixable, too old, ...". The surgeon turns sharply to her, sitting in his swivel chair, 
looks at her with his cold blue eyes, which contrast with his three-day-old beard, and says to her: "Ma' am, you have a massive ruptured rotator cuff, which cannot be repaired, in any case you are too old to be repaired... raise your right arm..." Françoise has difficulty raising her right arm; she is in pain. "You need to put on a reverse shoulder prosthesis and make an appointment with one of my secretaries; she will give you a date for the operation and organize everything for you. Here is my card with my website where everything is explained,... goodbye Madam, my assistant will accompany you...". The consultation lasted ten minutes; the Doctor did not get up from his seat and did not examine her. Françoise pays the bill for her exams and leaves without having made an operative appointment. She is shocked, worried incredulously about what just happened. The next day, she will see the physiotherapist who took care of her mother and who is still practicing. She explains how the consultation works. He asks her to see the MRI, which she could not recover ... She does not want to have an operation and decides to do the rehabilitation exercises given to her by the physiotherapist. After four months of rehabilitation, bodybuilding of the lowering of the humeral head and exercises that she did alone at home four times a day and once a week with the physiotherapist, she lifts her arm completely, has much less pain, and resumed her tennis games with her friends every Thursday. She has fun, laughs, even if she can no longer serve from above, because she has not recovered the muscle strength of her right arm.

Medicine and surgery evaluate in time and the historical view orients the patients to better and more adapted therapies. Some options are new; technology allows the use of robots, navigation, three-dimensional images, modern anaesthesia options allowing faster recovery, and one-day surgery for conditions that were difficult to treat in short hospital stays. However, the patient decision is mandatory especially in surgery dedicated to functional improvement such as the arthroplasty for arthritis. Heart bypass or lung resections are life-saving operations that should be performed; shoulder or knee arthroplasty improves mobility and life quality and does not interfere much with life expectancy. Improvement could be obtained also with conservative methods [5]. Traditionally, orthopaedic surgery improves life quality and restores hope. Therefore, the relation of trust between the surgeon and the patient is paramount. The time dedicated to each patient is a matter of quality and communication needs time. Clinics include thorough examination and evaluation of functional scores, ranges of motion, and comfort in daily activities. The scores should be documented and the patient should feel that the surgeon cares and includes a time dedicated to the physical examination. It is the surgeon who drives the clinic, and making it too neutral, impersonal, or too technical could determine a draw or waiver from the patient side.
In our first story, Raymonde had a shoulder replacement for arthritis improving her quality of life. In the second act, Françoise refuses shoulder arthroplasty and improves with physical therapy. She has some limitations but she is pain free, able to resume a normal life, and is happy. The first patient had a personalized relation with the surgeon and had trust in him, following his decisions and programs. The second patient chose not to have a procedure because the communication with the surgeon was nonexistent. She trusted the physical therapist that had experience with arthritic shoulders and actually she improved. She never returned to the famous surgeon's office.

The pandemic crisis interfered with patients' needs, expectations, and freedom of travel. Many "functional operations" were postponed or cancelled resulting in diminished quality of life. Some patients had to decide to wait or to choose physical therapy or alternative methods for manage their condition. Virtual clinics had basically the same effect and very few patients decided to have surgery after virtual clinics because they preferred to wait. This resulted eventually in diminished quality of life or bone and joint function.

Transition to "normal life" after a pandemic will include the progressive patient's return to clinics. Making the examination too technical and forgetting the clinical examination and evaluation could result in diminished quality of care.

\section{References}

1. Desmeules F, Dionne CE, Belzile É, Bourbonnais R, Frémont P (2009) Waiting for total knee replacement surgery: factors associated with pain, stiffness, function and quality of life. BMC Musculoskelet Disord 10:52. https://doi.org/10.1186/1471-2474-10-52

2. Scarlat MM, Sun J, Fucs PMB, Giannoudis P, Mavrogenis AF, Benzakour T, Quaile A, Waddell JP (2020) Maintaining education research and innovation in orthopaedic surgery during the COVID-19 pandemic. The role of virtual platforms. From presential to virtual front and side effects of the pandemic. Int Orthop 44(11):2197-2202. https://doi.org/10.1007/s00264-020-04848-8

3. Chawla SS, Whitson AJ, Schiffman CJ, Matsen FA 3rd, Hsu JE (2020) (2020) Drivers of lower inpatient hospital costs and greater improvements in health-related quality of life for patients undergoing total shoulder and ream-and-run arthroplasty. J Shoulder Elbow Surg 2020:S1058-2746(20)30904-6. https://doi.org/10. 1016/j.jse.2020.10.030

4. Craig RS, Goodier H, Singh JA, Hopewell S, Rees JL (2020) Shoulder replacement surgery for osteoarthritis and rotator cuff tear arthropathy. Cochrane Database Syst Rev 4(4):CD012879. https://doi.org/10.1002/14651858.CD012879.pub2

5. Mahendira L, Jones C, Papachristos A, Waddell J, Rubin L (2020) (2020) Comparative clinical and cost analysis between surgical and non-surgical intervention for knee osteoarthritis. Int Orthop 44(1):77-83. https://doi.org/10.1007/s00264-019-04405-y

Publisher's note Springer Nature remains neutral with regard to jurisdictional claims in published maps and institutional affiliations. 